\title{
Angelo Anzalone, Lo humano de los derechos humanos
}

(2021) Dykinson

Madrid, $220 \mathrm{pp}$.

\author{
Adolfo Jorge Sánchez Hidalgo \\ Universidad de Córdoba \\ ORCID ID 0000-0002-4155-5630 \\ ji2sahia@uco.es
}

Cita recomendada:

Sánchez Hidalgo, A. J. (2021). Angelo Anzalone, Lo humano de los derechos humanos. Eunomía. Revista en Cultura de la Legalidad, 21, pp. 475-478.

doi: https://doi.org/10.20318/eunomia.2021.6378

Recibido / received: 07/05/2021

El hombre vive y convive, existe y coexiste; sabe manifestarse en lo ético, es capaz de agregarse en lo político y suele encontrar vías de conciliación en lo jurídico. Las relaciones que se establecen entre las expresiones éticas, políticas y jurídicas se caracterizan por ser unas relaciones de tensión, donde, según textos y contextos, se buscan ciertos límites para que unos elementos se presenten como productos y $-\mathrm{a}$ la vez- medios de control de los otros. La búsqueda de equilibrio entre estas tensiones representa el problema principal que inquieta a estudiosos y operadores sociales -en todos los niveles-, pues suele estar en juego la consideración del ser humano como valor en sí mismo, como fin en sí mismo; es decir la consideración de la dignidad humana como fundamento básico del fenómeno jurídico, algo que comporta -o debería comportar- una concepción en virtud de la cual toda instancia poderosa política y/o estatal- debe prestarle servicio con responsabilidad, rigor y prudencia. Todo ello, obviamente, a través de un adecuado y fundamentado manejo de las herramientas jurídicas. En cualquier caso, el ser humano, individuo en constante relación e interacción con su tejido comunitario, debe ser capaz de actuar -en comúncon alto sentido de responsabilidad, implicándose $-y$ no esquivándola- en la búsqueda de un itinerario de responsabilidad para la humanidad.

Con total seguridad, podemos sostener que el núcleo de las consideraciones anteriores se corresponde con el centro de gravedad permanente de la obra del profesor Angelo Anzalone, quien muestra una gran preocupación por rescatar lo que de humano reside en las principales manifestaciones jurídicas. El Profesor Anzalone 
se licenció en su tierra natal, para ser exactos en las Universidades de Palermo y Enna, en la isla de Sicilia; obtuvo el título de Doctor en Derecho por la Universidad de Córdoba, donde actualmente desempeña sus principales actividades docentes e investigadoras. Se ocupa principalmente de la impartición de Teoría del Derecho, Teoría de los Derechos Humanos y Filosofía del Derecho, así como de diversas asignaturas del máster interuniversitario en Cultura de Paz, Conflictos, Educación y Derechos Humanos. Ha realizado estancias de investigación en diversas universidades europeas y en su trayectoria de investigación destacan las contribuciones sobre el neoidealismo y el iusnaturalismo hispanoitaliano, teoría comunicacional del derecho, cambios tecnológicos y derecho o, como en el caso de la obra que estamos analizando, teoría de los derechos humanos. Como puede apreciarse del título de su libro, el principal objeto de análisis está constituido por la expresión ética, política y jurídica que a lo largo de la historia más reciente ha sido registrada con el nombre de «derechos humanos». Precisamente por considerarlos como la derivación más directa de lo que de humano reside en el hombre, el análisis que el autor dedica a los derechos humanos es de tipo pluridimensional, ya que, no limitándose a un mero estudio lingüístico, lógico, técnico y formal, nos propone una lectura filosófico-cultural de estas controvertidas herramientas jurídico-políticas. Una perspectiva que, a su vez, se erige a vía de rescate y salvación para el funcionamiento práctico de una abstracta declaración de intenciones; una declaración ciertamente noble, pero necesitada de comprensión y actuación.

En general, el gran número de fuentes bibliográficas presente en esta monografía está equilibradamente repartido en todos sus capítulos, puesto que siempre encontramos un número significativo de citas que completan y enriquecen el texto principal, incrementando de este modo la recompensa que el lector podrá obtener con su lectura. De hecho, el conjunto de notas, menciones y argumentos de autoridad recogidos oportunamente a lo largo de la obra, ofrece, en cada apartado temático, nuevas sendas especulativas que el lector puede aprovechar para dirigirse, con cierta facilidad, a otras fuentes documentales que complementan la información sistematizada y elaborada en este libro. En particular, cabe destacar como el profesor Angelo Anzalone admite que determinadas contribuciones, firmadas por autores de reconocido prestigio, han sido de gran valor en la elaboración de su estudio. En el ámbito internacional, se refiere, entre otros, a Norberto Bobbio, Sergio Cotta, Benedetto Croce, Luigi Ferrajoli, Francesco D'Agostino, Francesco Viola, Claudio Sartea, Benedicto XVI, San Juan Pablo II, Hans Jonas, Robert Spaemann. En el panorama filosófico español, a Javier Hervada, Jesús Ballesteros, Francisco Carpintero, Gregorio Robles, Andrés Ollero, Antonio Enrique Pérez Luño, José Justo Megías, Ángela Aparisi, Encarnación Fernández, Fernando Llano y Diego Medina. Con ellos, junto a otros muchos interesantes pensadores, se analizan temáticas muy controvertidas y a través de ellos el lector podrá adquirir una visión crítica del panorama literario existente, así como alcanzar una mejor comprensión del pensamiento teórico y filosófico sobre los derechos humanos, encontrando un rumbo de lectura que se auto-declara responsable con la función humanizadora de lo jurídico.

En el primer capítulo se nos presenta el «sugestivo y persistente debate» (Anzalone, 2021, p. 25) en materia de pretendida universalidad y necesaria historicidad de los derechos humanos; en el segundo capítulo se reflexiona sobre la "fértil relación» (p. 49) que transcurre entre el hombre, los productos de su actividad intersubjetiva y, entre ellos, el derecho; el tercer capítulo está dedicado en su totalidad a la idea de dignidad humana, con el objetivo de advertir sobre las potencialidades positivas y negativas de su «doble rostro» (p. 71); el problema del fundamento de los derechos humanos, erigido a "problema metafísico» (p. 101) por antonomasia y ubicado en una «necesaria complementariedad entre fenómeno ético y expresión 
jurídica» (p. 91), ocupa el cuarto capítulo de este estudio monográfico; la interesante discusión acerca de los deberes humanos, entendida como una vía para recuperar la «responsabilidad perdida» (p. 153), y la reivindicación de sistemas educativos cónsonos a las exigencias que encarnan dichas expresiones jurídicas, constituyen el objeto de análisis crítico que encontramos perfilado, respectivamente, en los capítulos quinto y sexto. El profesor Anzalone, en cada uno de estos capítulos, pretende trasmitir una concepción en virtud de la cual es posible predicar una universalidad de los derechos humanos, ya que estos derechos pueden ser de todos, y en todas partes, pero solo a condición de que a su mínimo objetivo se acompañe una equilibrada diversificación de condiciones histórico-sociales. Unas condiciones concretas que representan, en suma, el motor dinámico de toda expresión jurídica. Para que los derechos humanos alcancen la categoría de eficaces instrumentos para la defensa de las íntimas instancias de la dignidad humana, en toda circunstancia de potencial peligro, presentándose, pues, como límites positivos y negativos a las diferentes instancias de poder, públicas o privadas; el autor considera imprescindible la promoción de una sana cultura en derechos humanos. El lector podrá fácilmente comprender que el objetivo, de acuerdo con el hilo conductor del trabajo, consiste en encontrar lo que de humano reside en estos derechos, buscando de este modo unas vías para recuperar el sentido de deber y responsabilidad al que tanto se apela en los capítulos finales del libro.

Apostando por una vía intermedia, equilibrada y dinámica, se nos recuerda la trascendencia práctica que puede tener una concepción «integrada e integrante de la esencia ontológica y de la visión moral de la dignidad» (p. 196). El profesor Anzalone prefiere no catalogar la dignidad humana como una dote, ni como una prestación, es decir apuesta por una no justificación de la idea de dignidad humana y, por el contrario, opta por reunir las dos principales aproximaciones especulativa a la noble noción: por una parte, destaca el valor de las que conectan la dignidad a determinadas características ontológicas; por otra, intenta demostrar -probablemente con éxito- el buen sentido de aquellas tendencias teóricas que relacionan la dignidad con el conjunto de circunstancias específicas que impulsan el devenir histórico de la humanidad. La intersubjetividad humana jugará un papel esencial, pues al considerar el hombre como lo que realmente es, por tanto, un ser social y personal, sujeto de derechos, pero también de deberes «para y con los demás» (p. 203), el Profesor de la Universidad de Córdoba resalta la grandeza del hombre-persona, representando su dignidad el presupuesto decisivo, el valor fundamental y el fin último que permiten la inteligibilidad del mundo en que vivimos. Dejándose guiar por las enseñanzas del ilustre italiano Sergio Cotta y por las del reconocido pensador portugués Antonio Castanheira Neves, el autor apela a la «coexistencia» (pp. 124-125 y 152-153) y a la indispensable, sana y genuina mediación comunitaria de la persona humana, un ente que no podrá realizarse plenamente, ni ser respetada adecuadamente, si opta por la vía de la enajenación, de la perdición o de la degradación «en su solitaria personalidad» (p. 203).

La investigación de la justificación ultima, es decir de la esencia fundamentadora de los derechos humanos, representa una parte esencial del trabajo monográfico en examen. Con ella se pretende acceder a una mejor comprensión de los motivos intrínsecos al reconocimiento y a la proclamación de estos derechos, algo que, a juicio del profesor Anzalone, «contribuye al reforzamiento de su protección y eficacia práctica» (p. 198). Temiendo las desviaciones del «peligroso instrumento legislativo» (Ibid.), se nos advierte que la búsqueda del fundamento de los derechos humanos no es una labor ilusoria, tratándose, por el contrario, de una imprescindible reflexión filosófico-jurídica sobre el estatuto ontológico del hombre y el tejido relacional que le rodea. Por ello, según el autor, no resultaría conveniente aparcar la cuestión del fundamento, en cuanto equivaldría a fomentar escepticismos y relativismos útiles 
al «estado-providencia» (p. 183). Nada más concreto y objetivo, por tanto, que la búsqueda de un adecuado fundamento de los derechos humanos; nada más abstracto y peligrosamente instrumentalizable, por el contrario, que el supuesto consenso político y jurídico positivizado, argumento frecuentemente utilizado para eludir la problemática filosófica. Este discurso -que se va desarrollando a partir del conjunto de las anteriores reflexiones sobre la persona, su dignidad y el fundamento de sus más básicas exigencias- lleva el autor a interrogarse «sobre la supervivencia de un sentido de responsabilidad que, últimamente, anda perdido» (p. 200). El profesor Anzalone invoca una prudencia responsable para no renunciar definitivamente a la ardua tarea de atender unos deberes que todos deberíamos cumplir sin más, es decir sin que necesariamente se intente jerarquizar entre ellos algo que considera poco útil y también inoportuno-: se refiere al deber de luchar contra la pobreza extrema, al de educar y compartir el conocimiento, al de ser respetuosos en el ejercicio de sus propios derechos, al de saber enfrentarse a situaciones de desigualdades extremas, al de preservar la vida humana, respetando el medio ambiente y amando la familia; al de cultivar proyectos comunes en dinámicas de solidaridad, sin dejarse vencer por la tentación del abandono o del egoísmo.

Apoyándose parcialmente en las conocidas aportaciones de Max Weber y de Hans Jonas, el autor sigue reivindicando la necesidad de una reflexión metafísica y la conveniencia de una fundamentación ontológica, considerando, por ejemplo, que la creencia en un orden ético sustancial y presente en nuestras vidas, que debe ser escrupulosamente custodiado, es motivo de esperanza. Ese orden requeriría equilibrio, prudencia y respeto de la vida humana, en una óptica de responsabilidad «para y con la especie humana de cara al futuro» (p. 160). Para ello, el profesor Anzalone utiliza los argumentos de Francisco Carpintero Benítez para insistir sobre la importancia que tiene el conocimiento y el respeto de «ciertas realidades que pueden ser descifradas solamente desde un plan metafísico», unas realidades de las que, además de su percepción sensorial, es posible predicar su existencia. La aproximación a los derechos humanos, en este discurso, representaría también una base para poner en marcha una equilibrada «acción educativa dotada de un bloque axiológico-valorativo imperecedero» (pp. 161 y 201). Hegel, Marx, Vico y Croce le sirven al autor de este interesante estudio como trampolín para reivindicar un adecuado conocimiento y una acertada valoración del devenir histórico, un paso esencial para descubrir el auténtico sentido que el conjunto de acciones humanas va adquiriendo en el tiempo; por otro lado, estas reflexiones le sirven también para reclamar la promoción de sistemas educativos a la altura de la cultura y del saber, adecuados para prestar un noble servicio a la humanidad, y, lo que es más importante, absteniéndose de jugar "con verdades artificiales o dogmas indescifrables» (p. 171). Este libro, en definitiva, es una llamada de atención para promover modelos educativos culturales y multinivel, algo de extraordinaria importancia para descubrir lo que de genuinamente humano reside en los derechos humanos. Este libro, en ultimísima instancia, es un requerimiento dirigido a la humanidad para que -tal y como concluye su autor, apoyándose en Jonas- «los efectos de nuestras actuaciones puedan resultar compatibles con la permanencia en la tierra de lo que de auténticamente humano reside en el hombre» (p. 189). 